Cite this: RSC Adv., 2014, 4, 19321

Received 20th November 2013 Accepted 7th April 2014

DOI: $10.1039 / c 3 r a 46869 k$

www.rsc.org/advances

\section{Role of membrane disturbance and oxidative stress in the mode of action underlying the toxicity of differently charged polystyrene nanoparticles}

\author{
Sourav Bhattacharjee, ${ }^{* a b}$ Dmitry Ershov, ${ }^{c}$ Mohammed A. Islam, ${ }^{b}$ Angela M. Kämpfer,
}

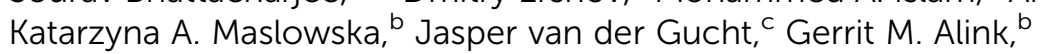

Antonius T. M. Marcelis, ${ }^{a}$ Han Zuilhof $^{a}$ and Ivonne M. C. M. Rietjens ${ }^{\star b}$

Surface charge is often hypothesized to influence toxicity of nanoparticles (NPs) including polymeric nanoparticles (PNPs) while oxidative stress is considered to be an important mode of action (MOA) for such toxicity. In order to investigate the role of membrane disturbance and oxidative stress in the MOA of PNPs, the cytotoxicity and a range of related cellular endpoints induced by monodisperse, fluorescent, cationic and anionic polystyrene nanoparticles (PSNPs) of 50 and $100 \mathrm{~nm}$ sizes were investigated in vitro in macrophage NR8383 cells. Only amine-terminated cationic PSNPs exhibited cytotoxicity which was accompanied by induction of intracellular reactive oxygen species (ROS), increased levels of cytoplasmic free calcium, a reduced phagocytic index, a reduced mitochondrial membrane potential $\left(\Delta \Psi_{\mathrm{m}}\right)$ and a decreased intracellular ATP content with the effects being more pronounced for $50 \mathrm{~nm}$ than $100 \mathrm{~nm}$ PSNPs. Both cationic and anionic PSNPs were found to increase the roughness of the cell membrane with the effect being more profound for cationic PSNPs. The pattern of protection by cellular antioxidants against the effects induced by positive PSNPs was similar to the pattern of protection against effects induced by the mitochondrial electron transport disrupting agent 2,4-dinitrophenol (DNP) and dissimilar to that for protection against the model compound for oxidative stress, i.e. hydrogen peroxide $\left(\mathrm{H}_{2} \mathrm{O}_{2}\right)$. Surface charge influences the cellular interaction for NPs. The results collectively indicated that membrane interaction, and disturbance of the mitochondrial electronic transport chain (ETC) may represent a principal mechanism of toxicity for cationic PSNPs resulting in ROS production and oxidative stress as secondary effects.

\section{Introduction}

Nanotechnology in recent years has experienced unprecedented growth with its applications ranging from energy production to food technology and medicine. The increase in nanotechnology-based products also raises the concern for health related aspects ${ }^{\mathbf{1}, \mathbf{2}}$ with regards to the inevitable human exposure. One of the less understood topics related to nanotoxicological research is the factor(s) that influence the interaction between nanoparticles (NPs) and cells and the mode of action (MOA) underlying such cellular toxicity. Surface charge and particle size are often hypothesized to be the most important factors that influence cellular toxicity of NPs. ${ }^{3-5}$ With successful application of polymer engineering, different polymeric nanoparticles

${ }^{a}$ Laboratory of Organic Chemistry, Wageningen University, Dreijenplein 8, $6703 \mathrm{HB}$ Wageningen, The Netherlands

${ }^{b}$ Division of Toxicology, Wageningen University, Tuinlaan 5, 6703 HE Wageningen, The Netherlands. E-mail: ivonne.rietjens@wur.nl

${ }^{c}$ Laboratory of Physical Chemistry and Colloid Science, Wageningen University, Dreijenplein 6, 6703 HB Wageningen, The Netherlands
(PNPs) with diverse physico-chemical properties (like biodegradability, fluorescence etc.) can be synthesized. This provides a unique tool for the toxicologists to investigate how surface charge and particle size might influence cellular interactions and toxicity of PNPs including their MOA. Hence, an investigation into the role of surface charge on the cellular interaction and MOA for cytotoxicity of PNPs is timely and justified.

Oxidative stress caused by the induction of intracellular reactive oxygen species (ROS) production by different NPs is a popular model to explain the cytotoxicity. ${ }^{6-8}$ However, the source of cellular ROS still remains unclear. It is possible that NPs can react with a wide variety of biomolecules producing radicals, like ROS. Simultaneously, some recent reports identified intracellular mitochondria as target organs for different NPs. Charged NPs can interact with intracellular mitochondria and dissipate the mitochondrial membrane potential $\left(\Delta \Psi_{\mathrm{m}}\right)$. In continuation to a possible deterioration of mitochondrial physiology after exposure to charged NPs, an increase in the intracellular calcium can be apprehended. Previously, some groups reported an increase in intracellular calcium after exposure to cationic NPs. ${ }^{\mathbf{9} 10}$ This is an interesting finding as an 
increase in intracellular calcium can trigger apoptotic pathways. A disturbance in mitochondrial membrane physiology can also disrupt the electron transport chain (ETC) and induce the production of ROS in addition to causing cellular ATP depletion. Then the question may be raised whether the ROS production is the cause of the cytotoxicity or rather a secondary effect occurring after ATP depletion or other effects following disruption of the mitochondrial function? To investigate the importance of ROS production and resulting oxidative stress as a mechanism of cytotoxicity of PSNPs, cytotoxic amine-terminated cationic PSNPs (PSNP- $\mathrm{NH}_{2}$ ), and anionic acid-terminated PSNPs (PSNP-COOH) which did not show any cytotoxicity, were tested for ROS production, cytotoxicity and a range of related cellular endpoints in macrophage NR8383 cells in which antioxidant levels were artificially modified. For comparison, similar experiments as done with the PSNPs, were performed using the mitochondrial ETC disrupting agent, 2,4-dinitrophenol (DNP) and with the known inducer of oxidative stress, hydrogen peroxide $\left(\mathrm{H}_{2} \mathrm{O}_{2}\right)$.

The main objectives of this article are therefore to systematically investigate the effect of surface charge in the cytotoxicity of well-characterized PSNPs as well as to understand the MOA of such toxicity in detail. The importance of oxidative stress as MOA in such toxicities of charged NPs was also probed.

\section{Results}

\section{Characterization of PSNPs}

The characterization of the PSNPs was done by measuring the size and polydispersity index (PDI) by dynamic light scattering (DLS), surface potential (as an indication of surface charge) by $\zeta$ potential measurements and imaging by atomic force microscopy (AFM). The results are shown in Fig. 1 and Table 1, respectively.

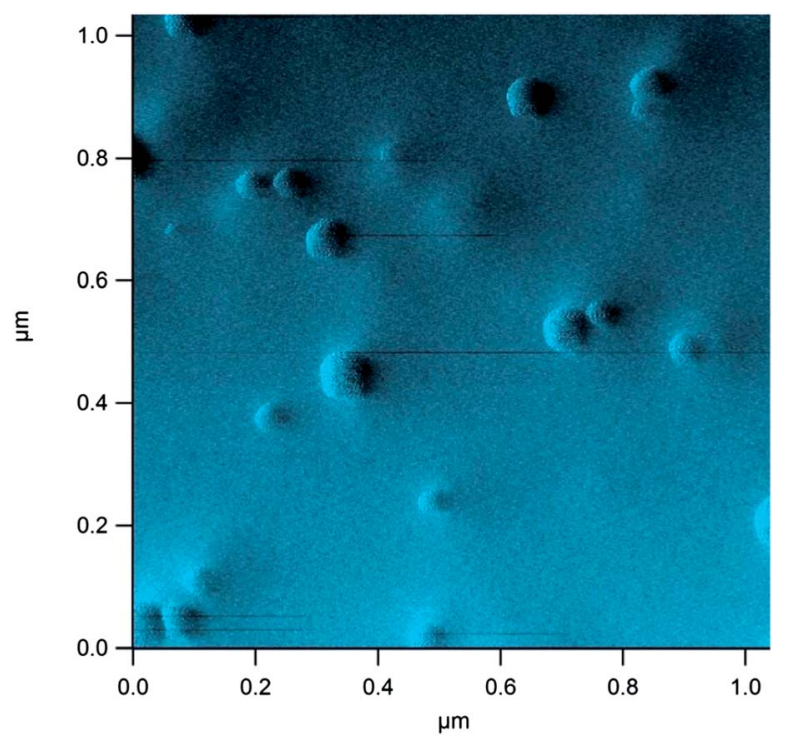

Fig. 1 AFM (contact tapping mode) picture of $100 \mathrm{~nm}$ PSNPs on a mica surface. The different PSNPs are at different height levels on the mica surface.
From Fig. 1 (AFM image), the PSNPs could clearly be visualized with mild variation of sizes arising due to embedding of the PSNPs in the soft layer. The dispersion of the PSNPs both in water and cell culture medium (DMEM/F12-K) containing 10\% fetal calf serum (FCS) were confirmed by DLS and the PDI of the PSNPs in aqueous dispersions were found to be very low (Table 1). While in cell culture medium containing FCS, an increase in size for the PSNPs could be observed (after $4 \mathrm{~h}$ ) which resulted from the surface adsorption of proteins added to the cell culture medium via FCS. However, despite the increase in size in the cell culture medium, the PSNPs continued to be quite monodisperse as indicated by the PDI and shown in Table 1 . The PSNPs were quite stable both in aqueous and cell culture medium over at least a month (as determined by DLS) and did not show any sedimentation or aggregation.

\section{Cytotoxicity measurement by the MTT and phagocytic index} (PI) assay

The cytotoxicity of the PSNPs was measured by the MTT (Fig. 2) and the PI (Fig. 3) assays. At the concentrations tested (0-100 $\mu \mathrm{g}$ $\mathrm{ml}^{-1}$ ), only the cationic PSNPs showed signs of cytotoxicity in both these assays. For the anionic PSNPs, no such cytotoxicity could be observed. The $\mathrm{EC}_{50}$ values obtained from the MTT and PI assays are presented in Table 2. Although not always statistically significant $(p<0.05)$, a size-dependent effect on the cytotoxicity of PSNPs could be observed. In this case, the smaller cationic PSNPs (50 nm) were relatively more cytotoxic than the larger ones $(100 \mathrm{~nm})$.

\section{Protective effects of vitamins $\mathrm{E}$ and $\mathrm{C}$ against the cytotoxicity of DNP, PSNP-NH $\mathrm{NH}_{2}$ and $\mathrm{H}_{2} \mathrm{O}_{2}$}

To investigate the role of oxidative stress in the MOA of the PSNP-NH $\mathrm{N}_{2}$ the protective effects of vitamins $\mathrm{E}$ and $\mathrm{C}$ were investigated and compared to the protection by these antioxidants against the mitochondrial ETC disrupting agent 2,4dinitrophenol (DNP) and the known inducer of oxidative stress, hydrogen peroxide $\left(\mathrm{H}_{2} \mathrm{O}_{2}\right)$. The results obtained are shown in Fig. 4. From the results on the protective effects of anti-oxidants compared to the toxicity of PSNP- $\mathrm{NH}_{2}$, it could be seen that, although vitamins $\mathrm{E}$ and $\mathrm{C}$ were capable of providing some protection against cytotoxicity of $\mathrm{PSNP}^{-\mathrm{NH}_{2}}$, the protection failed to be significant $(p<0.05)$. The pattern of protection by vitamins $\mathrm{E}$ and $\mathrm{C}$ against the cytotoxicity induced by positive PSNPs was similar to the pattern of protection against the cytotoxicity of the mitochondrial electron transport disrupting agent DNP but dissimilar to that for protection against cytotoxicity of the model compound for oxidative stress $\mathrm{H}_{2} \mathrm{O}_{2}$.

Effect of modulating intracellular levels of glutathione (GSH) on the cytotoxicity caused by DNP, PSNP- $\mathrm{NH}_{2}$ and $\mathrm{H}_{2} \mathrm{O}_{2}$

The effect of modulating the intracellular levels of GSH by preexposure to buthionine sulphoximine (BSO) or $\mathrm{N}$-acetyl cysteine (NAC) on the cytotoxicity caused by DNP, PSNP- $\mathrm{NH}_{2}$ and $\mathrm{H}_{2} \mathrm{O}_{2}$ are shown in Fig. 5. Both decreasing the intracellular GSH levels by incubation with BSO and increasing these levels of cellular anti-oxidants by incubation with NAC, did not significantly ( $p<$ 
Table 1 Characterization data of different PSNPs

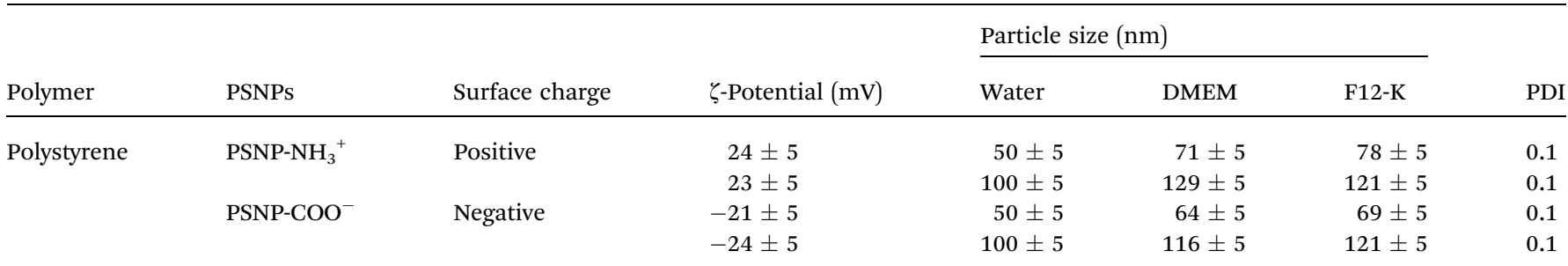

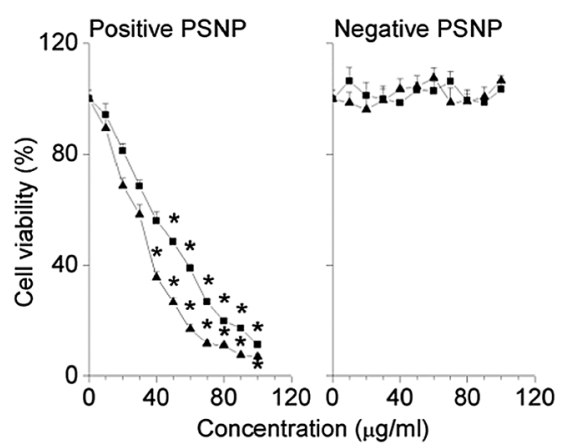

Fig. 2 Cell viability measured by the MTT assay and expressed as \% of negative control $\left(0 \mu \mathrm{g} \mathrm{ml}^{-1}\right)$ after $4 \mathrm{~h}$ exposure of NR8383 cells to positive and negative PSNPs of $50(\boldsymbol{\Delta})$ and $100(\boldsymbol{\square}) \mathrm{nm}$ sizes $(n=3)$. The asterisk $(*)$ symbol signifies statistical difference from the negative control at $p<0.05$

0.05) increase or decrease in cytotoxicity of DNP and PSNP- $\mathrm{NH}_{2}$. However, for $\mathrm{H}_{2} \mathrm{O}_{2}$ the exposure to BSO and NAC significantly increased and decreased the cytotoxicity, respectively. Thus, also in these experiments the pattern of cytotoxicity and cellular protection observed for $\mathrm{PSNP}-\mathrm{NH}_{2}$ resembled that of the ETC uncoupler DNP more than that of the oxidative stress model compound $\mathrm{H}_{2} \mathrm{O}_{2}$.

\section{Mitochondrial membrane potential $\left(\Delta \Psi_{m}\right)$ assessment}

In order to investigate the probable effect of different PSNPs on intracellular mitochondria, the mitochondrial membrane potential $\left(\Delta \Psi_{\mathrm{m}}\right)$ was measured. Normally, an electrochemical gradient of 130-140 $\mathrm{mV}$ potential difference exists across the

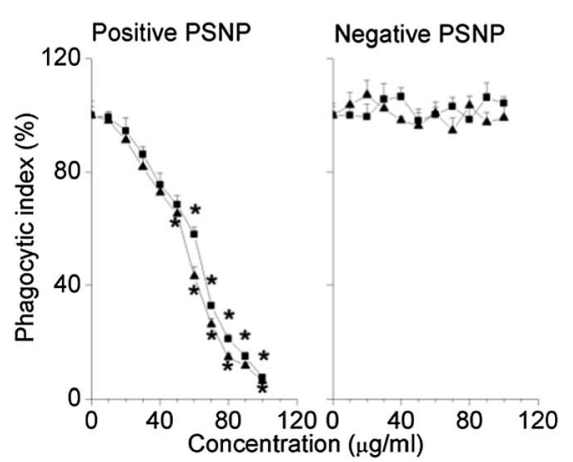

Fig. 3 Phagocytic index expressed as \% of negative control $\left(0 \mu \mathrm{g} \mathrm{ml}^{-1}\right)$ after $4 \mathrm{~h}$ exposure of NR8383 cells to positive and negative PSNPs of $50(\boldsymbol{\Delta})$ and $100(\boldsymbol{\square})$ nm sizes $(n=3)$. The asterisk (*) symbol signifies statistical difference from the negative control at $p<0.05$.
Table 2 The $E C_{50}$ values obtained from different experiments reported in this paper. No $\mathrm{EC}_{50}$ values were available for anionic PSNPs due to their non-toxicity in the tested concentration range

\begin{tabular}{llll}
\hline & & \multicolumn{2}{l}{$\mathrm{EC}_{50}\left(\mu \mathrm{g} \mathrm{ml}^{-1}\right)$} \\
\cline { 3 - 4 } Assay & Figure & $50 \mathrm{~nm}$ PSNP & $100 \mathrm{~nm}$ PSNP \\
\hline MTT & 2 & 33 & 35 \\
PI & 3 & 56 & 62 \\
$\Delta \Psi_{\mathrm{m}}$ & 6 & 38 & 33 \\
DCFH-DA & 7 & 54 & 68 \\
ATP & 9 & 63 & 66 \\
Calcium & 10 & 84 & 88
\end{tabular}

mitochondrial membrane ${ }^{11}$ with the outer side (towards the cytoplasm) being relatively positive compared to the inner side (towards the mitochondrial matrix). The results obtained are shown in Fig. 6 . The cationic PSNPs of both sizes $(50 \mathrm{~nm}>100$ $\mathrm{nm}$ ) caused a dose-dependent reduction in the $\Delta \Psi_{\mathrm{m}}$ within the tested concentration range $\left(0-100 \mu \mathrm{g} \mathrm{ml} \mathrm{m}^{-1}\right)$ in contrast to the anionic ones, which did not show any effect on the value of $\Delta \Psi_{\mathrm{m}}$. The corresponding $\mathrm{EC}_{50}$ values are given in Table 2.

\section{Measurement of intracellular ROS production by the DCFH- DA assay}

The DCFH-DA ( $2^{\prime}, 7^{\prime}$-dichlorofluorescein diacetate) assay was used to assess any induction in intracellular ROS production by different PSNPs. The results of the DCFH-DA assay are shown in Fig. 7. In contrast to the anionic PSNPs, the cationic PSNPs of

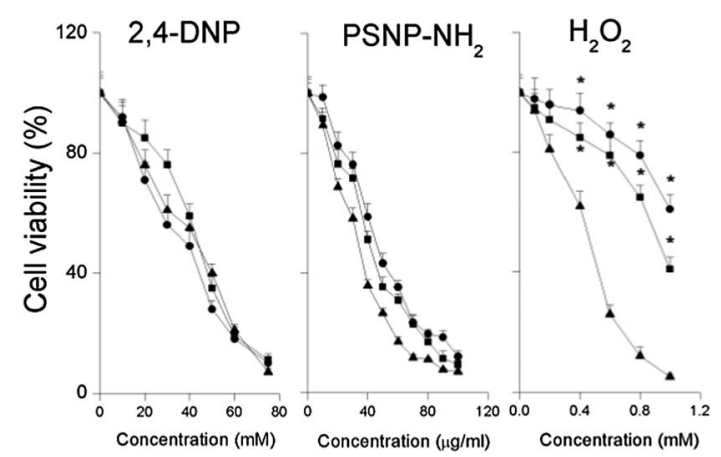

Fig. 4 Effects of vitamins E ( $\mathbf{a})$ and C (O) on cell viability in NR8383 cells after $4 \mathrm{~h}$ exposure to serial dilutions of DNP (0-75 mM), PSNP$\mathrm{NH}_{2}\left(0-100 \mu \mathrm{g} \mathrm{ml}^{-1}\right)$ or $\mathrm{H}_{2} \mathrm{O}_{2}(0-1 \mu \mathrm{M})(\boldsymbol{\Delta})$ as measured by the MTT assay $(n=3)$. The asterisk (*) sign marks significant differences $(p<$ $0.05)$ compared to the corresponding values without vitamin $E$ or $C$. 


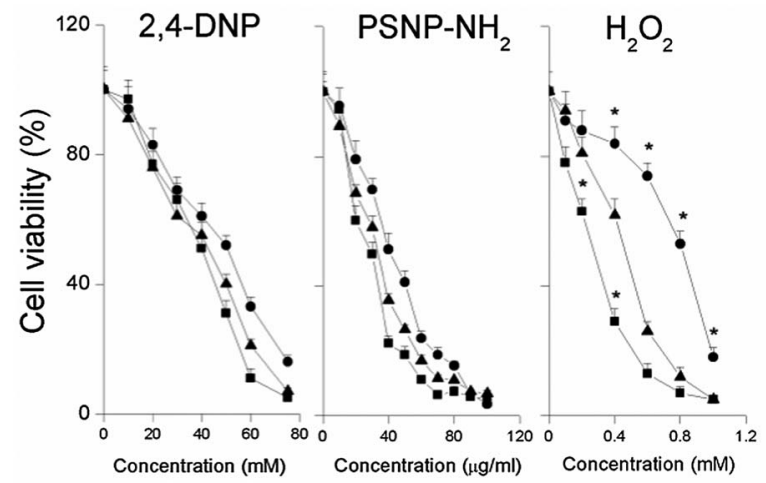

Fig. 5 Effects of BSO ( $\mathbf{a}$ ) and NAC ( ) on cell viability in NR8383 cells after $4 \mathrm{~h}$ exposure to serial dilutions of DNP $(0-75 \mathrm{mM}), \mathrm{PSNP}-\mathrm{NH}_{2}(0-$ $\left.100 \mu \mathrm{g} \mathrm{ml}^{-1}\right)$ or $\mathrm{H}_{2} \mathrm{O}_{2}(0-1 \mu \mathrm{M})(\mathbf{\Delta})$ as measured by the MTT assay $(n=$ 3). The asterisk $(*)$ sign marks significant differences $(p<0.05)$ compared to the corresponding values without BSO or NAC.

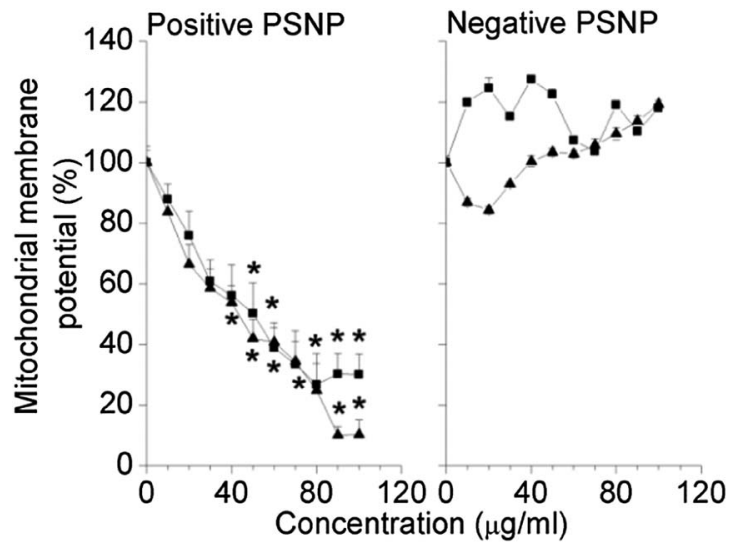

Fig. 6 Mitochondrial membrane potential $\left(\Delta \Psi_{m}\right)$ expressed as \% of negative control $\left(0 \mu \mathrm{g} \mathrm{ml}^{-1}\right)$ after $4 \mathrm{~h}$ exposure of NR8383 cells to positive and negative PSNPs of $50(\boldsymbol{\Delta})$ and $100(\boldsymbol{\square}) \mathrm{nm}$ sizes $(n=3)$. The asterisk (*) symbol signifies statistical difference from the negative control at $p<0.05$.

both sizes showed induction in ROS production, with the $50 \mathrm{~nm}$ PSNPs being more effective than the $100 \mathrm{~nm}$. The corresponding $\mathrm{EC}_{50}$ values are given in Table 2.

Induction of intracellular ROS measured by the DCFH-DA assay in presence of DNP, PSNP-NH $\mathrm{NH}_{2}$ and $\mathrm{H}_{2} \mathrm{O}_{2}$

Fig. 8 shows the induction of ROS in NR8383 cells after $4 \mathrm{~h}$ exposure to serial dilutions of DNP, PSNP-NH2 and $\mathrm{H}_{2} \mathrm{O}_{2}$. In the absence of vitamins $\mathrm{E}$ or $\mathrm{C}, \mathrm{H}_{2} \mathrm{O}_{2}$ showed maximal induction of ROS production $(>1100 \%)$ followed by the PSNP-NH $\mathrm{NH}_{2}(\sim 563 \%)$ and DNP ( $\sim 500 \%)$, all compared to the negative control. Vitamins $\mathrm{E}$ and $\mathrm{C}$ suppressed the inductions of ROS for all three exposure agents markedly, to a level hardly above control values. The pattern of ROS production induced by $\mathrm{PSNP}-\mathrm{NH}_{2}$ resembled that of the ETC uncoupler DNP more than that of the oxidative stress model compound $\mathrm{H}_{2} \mathrm{O}_{2}$.

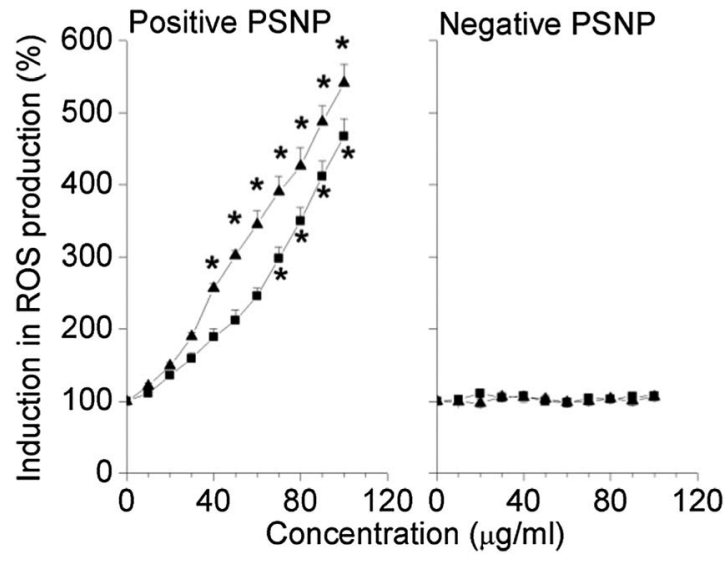

Fig. 7 Induction in intracellular ROS production expressed as \% of negative control $\left(0 \mu \mathrm{g} \mathrm{ml}^{-1}\right)$ after $4 \mathrm{~h}$ exposure of NR8383 cells to positive and negative PSNPs of $50(\boldsymbol{\Delta})$ and $100(\boldsymbol{\square})$ nm sizes $(n=3)$. The asterisk (*) symbol signifies statistical difference from the negative control at $p<0.05$.

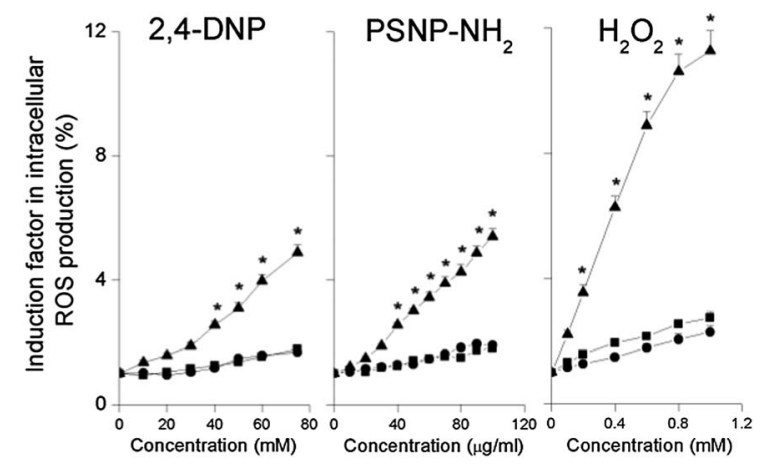

Fig. 8 Effects of vitamins $\mathrm{E}(\boldsymbol{\square})$ and $\mathrm{C}(\mathbf{O})$ on the intracellular ROS induction in NR8383 cells after $4 \mathrm{~h}$ exposure to serial dilutions of DNP $(0-75 \mathrm{mM})$, PSNP-NH $2\left(0-100 \mu \mathrm{g} \mathrm{m}^{-1}\right)$ or $\mathrm{H}_{2} \mathrm{O}_{2}(0-1 \mu \mathrm{M})(\boldsymbol{\Delta})$ as measured by the DCFH-DA assay $(n=3)$. The asterisk (*) sign marks significant differences $(p<0.05)$ compared to the negative control $(0$ $\mu \mathrm{gl}^{-1}$ ).

\section{Measurement of intracellular ATP content}

The intracellular ATP was measured in NR8383 cells after $4 \mathrm{~h}$ exposure to different PSNPs in order to further characterize the possible interaction of different surface charge bearing PSNPs with intracellular mitochondria. The results are shown in Fig. 9 with the corresponding $\mathrm{EC}_{50}$ values being shown in Table 2. For the cationic PSNPs, a dose dependent decrease in the cellular ATP content could be observed with the $50 \mathrm{~nm}$ PSNPs being more effective than the $100 \mathrm{~nm}$, in contrast to the anionic PSNPs which failed to show any such decrease in cellular ATP content at the concentrations tested $\left(0-100 \mu \mathrm{g} \mathrm{ml} \mathrm{m}^{-1}\right)$.

\section{Measurement of intracellular calcium}

The cellular calcium content was measured in NR8383 cells after $4 \mathrm{~h}$ exposure to serial dilutions $\left(0-100 \mu \mathrm{g} \mathrm{ml}^{-1}\right)$ of different PSNPs. The results are shown in Fig. 10 and the corresponding $\mathrm{EC}_{50}$ values are given in Table 2 . As expected, only the cationic 


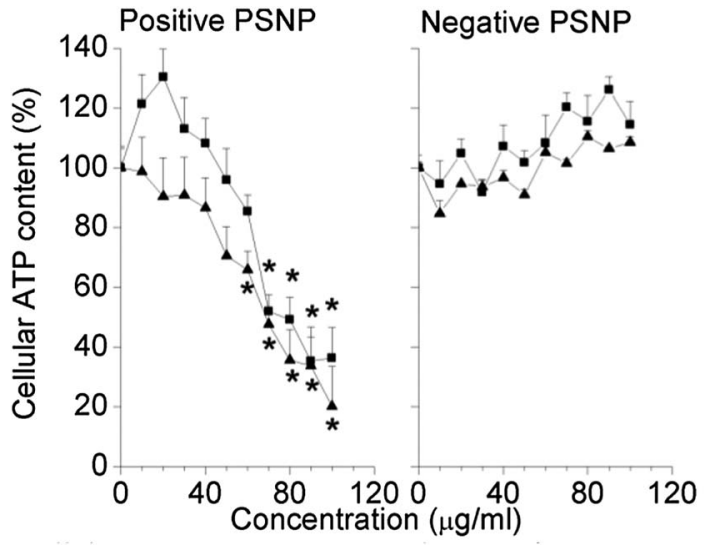

Fig. 9 Cellular ATP content expressed as \% of negative control ( $0 \mu \mathrm{g}$ $\mathrm{ml}^{-1}$ ) after $4 \mathrm{~h}$ exposure of NR8383 cells to positive and negative PSNPs of $50(\boldsymbol{\Delta})$ and $100(\boldsymbol{\square})$ nm sizes $(n=3)$. The asterisk (*) symbol signifies statistical difference from the negative control at $p<0.05$.

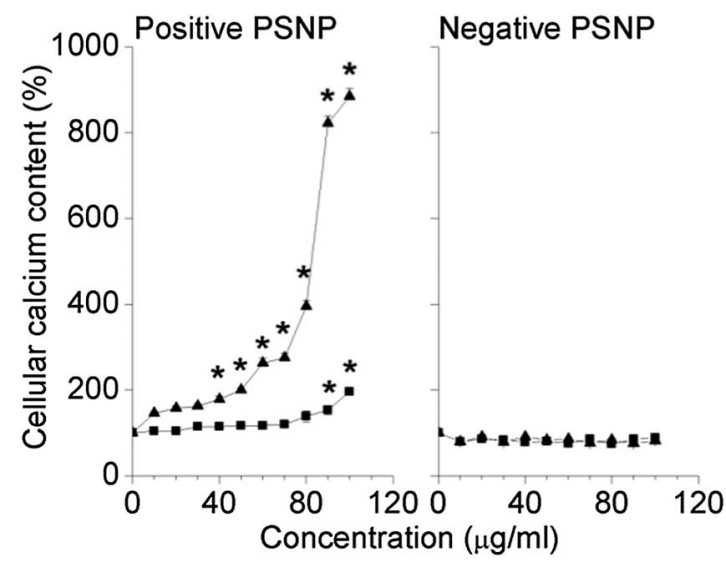

Fig. 10 Cytoplasmic free calcium content expressed as \% of negative control $\left(0 \mu \mathrm{g} \mathrm{m}^{-1}\right)$ after $4 \mathrm{~h}$ exposure of NR8383 cells to positive and negative PSNPs of $50(\boldsymbol{\Delta})$ and $100(\boldsymbol{\square})$ nm sizes $(n=3)$. The asterisk (*) symbol signifies statistical difference from the negative control at $p<$ 0.05 .

PSNPs (50 nm > $100 \mathrm{~nm}$ ) caused a dose dependent increase in the cytoplasmic free calcium levels whereas no such effects were observed for anionic PSNPs.

\section{Cellular uptake and cellular distribution of PSNPs as determined by CLSM}

The NR8383 cells were exposed to a non-toxic concentration (1 $\mu \mathrm{g} \mathrm{m} \mathrm{m}^{-1}$ ) of both cationic and anionic $100 \mathrm{~nm}$ PSNPs for $4 \mathrm{~h}$ before checking the cellular uptake and cellular distribution of the PSNPs. The results are shown in Fig. 11A. The CLSM technique was employed in order to characterize the uptake patterns as well as to perform quantitative assessment of the cellular uptake of PSNPs of different surface charges. The results from at least ten individual cells from three separate experiments were counted. The cationic PSNPs were taken up almost twice as much (Fig. 11B) as the anionic PSNPs. With a detailed analysis of the data it was found that cationic PSNPs showed more

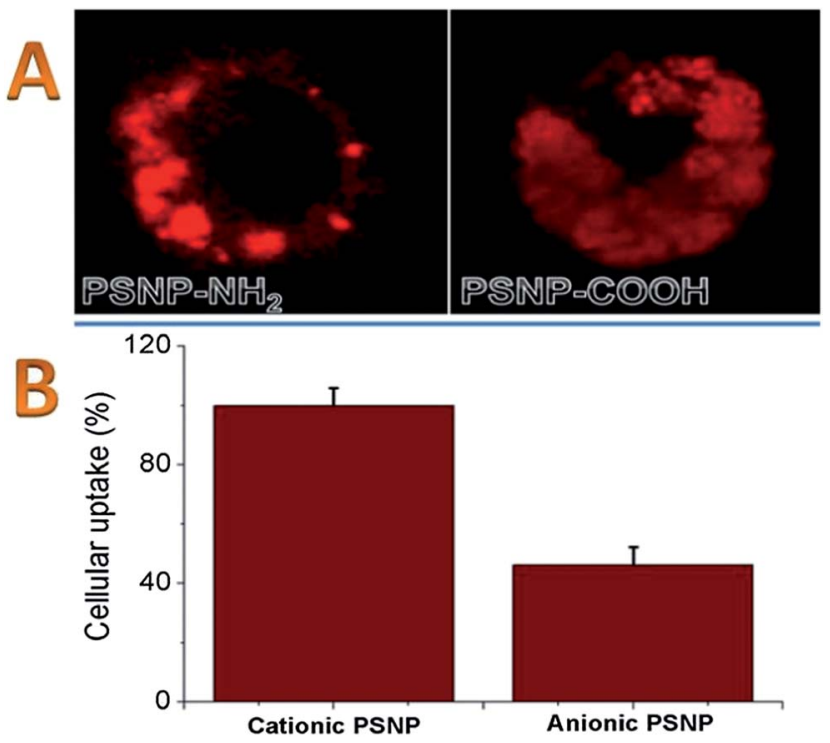

Fig. 11 (A) CLSM images of NR8383 cells $\left(\lambda_{\mathrm{ex}}=543 \mathrm{~nm}, \lambda_{\mathrm{em}}=620 \mathrm{~nm}\right)$ after $4 \mathrm{~h}$ exposure to positive (amine-terminated/PSNP-NH $\mathrm{H}_{2}$ ) and negative (acid-terminated/PSNP-COOH) 100 nm PSNP. (B) Relative cellular uptake of $100 \mathrm{~nm}$ cationic and anionic PSNP in NR8383 cells after $4 \mathrm{~h}$ exposure to non-toxic $1 \mu \mathrm{g} \mathrm{ml}^{-1}$ concentrations. Results are shown as mean \pm SEM. The uptake of the cationic PSNP was taken as $100 \%$. The results were expressed as an arithmetic mean of the CLSM data obtained from 20 individual cells from five separate experiments $(n=5)$. Scale bars show $10 \mu \mathrm{m}$.

interaction with the cellular periphery. For anionic PSNPs, no such enhanced interaction between the PSNPs and the cell membrane could be observed. Differences could also be seen in the intracellular distribution patterns of the two different surface charge bearing PSNPs. For anionic PSNPs, small vesicular structures could be seen inside the cells which were not seen for the cationic PSNPs. For the cationic PSNPs, the NPs were found to be diffusely distributed across the cytoplasm and also in the perinuclear regions.

\section{Integrity of cell membrane after exposure to PSNPs}

Calcein-AM assay. To investigate the effect of charged PSNPs on cellular membrane integrity, the calcein assay was performed where non-fluorescent calcein-AM (acetomethoxy) salt was administered which after entering cells is hydrolyzed into calcein and becomes fluorescent. By CLSM, the calcein inside the cells could be visualized and this is a standard technique for testing the integrity of the cell membrane. ${ }^{12}$ From the results obtained (Fig. 12), it can be seen that for the cationic PSNPs at a non-cytotoxic concentration of $1 \mu \mathrm{g} \mathrm{ml}{ }^{-1}$, pouches of calcein leaked out of the cell pointing at a compromised state of the cell membrane. In contrast, for the anionic PSNPs (also at $1 \mu \mathrm{g}$ $\mathrm{ml}^{-1}$ ), the integrity of the cell membrane was comparable to that of a normal NR8383 cell (control). This indicates that cationic PSNPs could actually harm the structural integrity of the cell membrane.

AFM. The results of the AFM investigation are shown in Fig. 13. The cationic PSNPs caused a higher disruption of cell 

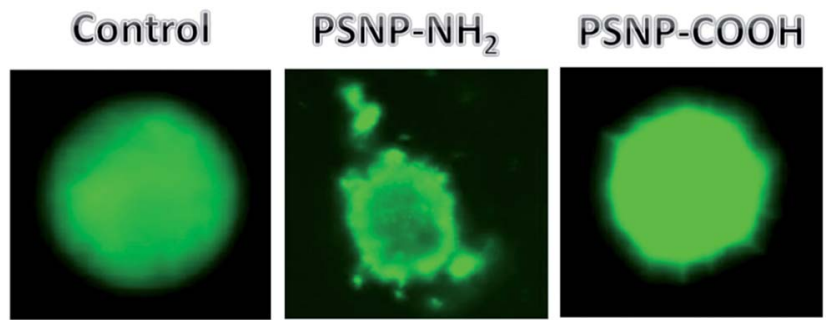

Fig. 12 Calcein assay ( $\lambda_{\mathrm{ex}}=488 \mathrm{~nm}, \lambda_{\mathrm{em}}=538 \mathrm{~nm}$ ) of NR8383 cells after $4 \mathrm{~h}$ exposure to a non-toxic $\left(1 \mu \mathrm{g} \mathrm{ml}^{-1}\right)$ concentration of $100 \mathrm{~nm}$ positive PSNP-NH $\mathrm{N}_{2}$ and negative PSNP- $\mathrm{COOH}$. The positive PSNPS caused discontinuity on the cell surface with calcein coming out, which is absent for negative PSNPs.
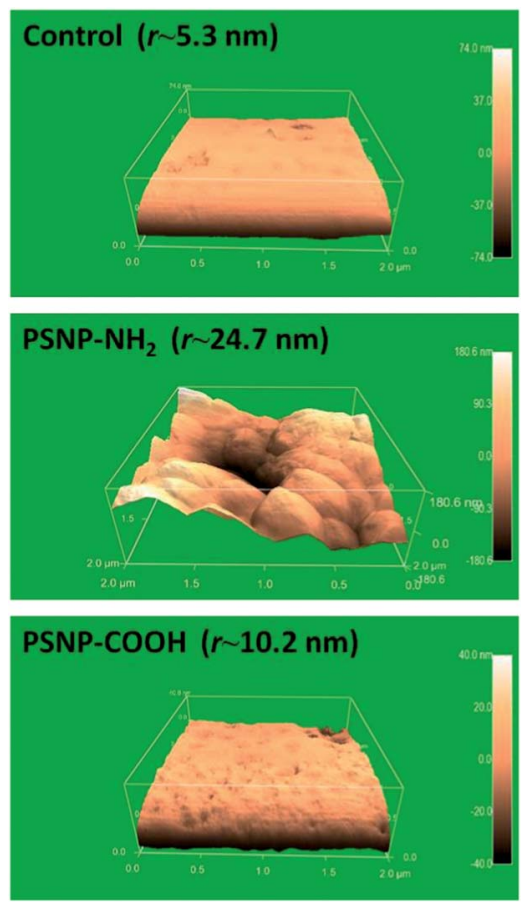

Fig. 13 AFM (contact tapping mode) on NR8383 cells placed on a mica surface after $4 \mathrm{~h}$ exposure to non-toxic $\left(1 \mu \mathrm{g} \mathrm{ml}^{-1}\right)$ concentrations of positive (amine terminated) and negative (acid terminated) 100 $\mathrm{nm}$ PSNPs. The positive PSNP created holes on the cell surface alike the negative PSNPs $(n=5)$.

surface and increased the overall roughness of the surface. The normal mean roughness of NR8383 cells was found to be $\sim 5.3 \pm$ $1 \mathrm{~nm}$ whereas after exposure to the cationic PSNPs, the mean roughness showed an almost five-fold increase $(\sim 24.7 \pm 5 \mathrm{~nm})$. Additionally, pores or holes of different sizes (at least $\sim 150 \mathrm{~nm}$ in size) could be observed on the surface. In contrary, for anionic PSNPs, the roughness of the NR8383 cell surface did increase but only to a much lesser degree $(\sim 10.2 \pm 3 \mathrm{~nm})$ and no such holes could be observed.

\section{Discussion}

The aim of this study was to investigate the role of membrane disturbance and oxidative stress in the MOA of the cytotoxicity of monodisperse, fluorescent PSNPs of different charge and size. To this point, various cellular endpoints were identified in order to better understand the mechanism of such toxicity including the importance of oxidative stress as primary or secondary mechanism of cytotoxicity. The major observations were: (1) the cationic PSNPs showed higher cytotoxicity as well as cellular uptake compared to the anionic PSNP, indicating an effect of surface charge; (2) a size-effect was also found since smaller $50 \mathrm{~nm}$ cationic PSNP were found to be more toxic compared to the bigger $100 \mathrm{~nm}$ cationic PSNP; (3) positively charged PSNPs can cause disruption of the ETC which in turn can act as an inducer of intracellular ROS production, reduction of the mitochondrial membrane potential $\left(\Delta \Psi_{\mathrm{m}}\right)$ and reduction of cellular ATP levels; (4) especially positive PSNP caused a disruption of the membrane integrity and pore formation could be visualized; (5) intracellular mitochondria were identified as a major target organelle in the cytotoxicity causing pathway; (6) the membrane disturbance as well as mitochondrial dysfunction were the principal mechanism of cytotoxicity (for cationic PSNPs) which further resulted in oxidative stress as secondary effect.

The PSNPs were either amine (PSNP-NH ${ }_{2}$ ) or acid terminated (PSNP-COOH) rendering them to be positively (PSNP- $\mathrm{NH}_{3}{ }^{+}$) or

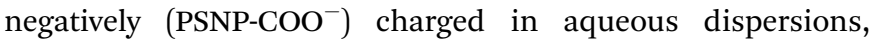
respectively. Both the PSNP- $\mathrm{NH}_{3}{ }^{+}$and $\mathrm{PSNP}-\mathrm{COO}^{-}$gave stable dispersions in water as well as in cell culture medium. However, in medium, an increase in the sizes of both the PSNPs was found. This was due to surface adsorption of proteins present in the cell culture medium. The surface adsorption of proteins on different engineered NPs has been investigated before and was found to influence the cellular interactions of PNPs. ${ }^{13,14}$ An interesting finding was that the cationic PSNPs overall showed a stronger increase in size as compared to the anionic ones. A possible explanation can be the electrostatic interactions between the surface charge of the PSNPs and the charge of these proteins. ${ }^{15}$ The proteins, like albumin, which are present in FCS are often negatively charged at normal $\mathrm{pH}$ and thus experience electrostatic attraction towards cationic PSNPs. This can be an explanation for the dissimilar growth in the sizes of cationic and anionic PSNPs in cell culture medium. Our cytotoxicity data are in line with reports where cationic NPs showed greater cytotoxicity as compared to anionic ones, both for polymer ${ }^{16}$ and inorganic NPs. ${ }^{17}$ It is still not clear on mechanistic grounds why cationic NPs, in general, are more cytotoxic than the anionic ones. A hypothesis put forward by some groups is that the cationic NPs are attracted by electrostatic interaction towards the (overall) anionic cell membrane and even other lipid based biomembranes, which makes their interactions with biomembranes easier as compared to that of the anionic ones. ${ }^{18}$ Similarly, size dependence in cytotoxicity of different NPs (with cytotoxicity inversely related to the sizes of NPs) has also been reported for other types of NPs. A clear understanding of the mode of action underlying this size-effect on the cytotoxicity of NPs is lacking although a hypothesis has been put forward that with decreasing size, NPs start becoming more reactive and hence, can react with a wider variety of biomolecules causing toxicity. It is also possible that with decreasing size, a higher $\%$ 
of the molecules in the NP get expressed on the surface, making smaller NPs relatively more reactive than the larger ones. ${ }^{19}$

With reference to several recent reports, a surface chargedriven interaction between $\mathrm{PSNP}_{-} \mathrm{NH}_{2}$ and the cellular membranes may be suggested as the major mode of action underlying the cytotoxicity of cationic PSNP- $\mathrm{NH}_{2} \cdot{ }^{20-23}$ Simultaneously, it was also mentioned that oxidative stress failed to explain several findings related to the primary mechanism of cytotoxicity for NP. The experiments with DNP and $\mathrm{H}_{2} \mathrm{O}_{2}$ were therefore intentionally chosen in order to delineate the role of intracellular ROS and oxidative stress in the MOA of PSNP- $\mathrm{NH}_{2}$. It was observed that the damage done by $\mathrm{H}_{2} \mathrm{O}_{2}$, which is a known inducer of oxidative stress, can be mitigated effectively by both vitamins $\mathrm{E}$ and $\mathrm{C}$. In contrast, these vitamins failed to significantly $(p<0.05)$ reduce cytotoxicity caused both by DNP or PSNP-NH $\mathrm{N}_{2}$. In fact, the protection patterns exhibited by vitamins $\mathrm{E}$ and $\mathrm{C}$ against the cytotoxicity of DNP and PSNP- $\mathrm{NH}_{2}$ showed an overall resemblance with each other and were clearly different from those obtained for $\mathrm{H}_{2} \mathrm{O}_{2}$. The data obtained by decreasing or augmenting the cellular GSH levels further supported this notion. It is reported that cationic $\mathrm{PSNP}-\mathrm{NH}_{2}$ caused a depletion of cellular GSH levels. ${ }^{24,25}$ Hence, external application of NAC should have largely curbed the cytotoxicity of PSNP$\mathrm{NH}_{2}$ if oxidative stress was the main driving event behind cytotoxicity. Our results matched with the very small amount of investigations where cellular membranes and mitochondria have been identified as cellular targets for NPs with cationic NPs showing deleterious effects on the $\Delta \Psi_{\mathrm{m}} \cdot{ }^{26}$ Given that the mitochondrial membrane is the location of the ETC, any disturbance in mitochondrial membrane physiology can be expected to hamper the ETC, disturbing the creation of the proton motive force, and thus the mitochondrial membrane potential $\left(\Delta \Psi_{\mathrm{m}}\right)$, ATP generation and the flow of electrons, of which the latter may result in ROS production as a secondary effect. This induction of intracellular ROS can cause oxidative stress. Previously various groups have hypothesized that oxidative stress is the mechanism of cytotoxicity of different NPs including PNPs. ${ }^{27,28}$ However, there is still controversy about what may be the source of the production of intracellular ROS. Some groups have reported that intracellular mitochondria can be a target organ for NPs. ${ }^{29,30}$

Our data showed for the first time, that for cationic PSNP$\mathrm{NH}_{2}$, it is not oxidative stress but the membrane interaction with cationic PSNP- $\mathrm{NH}_{2}$ (with possible ETC disruption) that propels the cytotoxicity pathway, including the induction of ROS as a secondary effect. With evidence pointing towards cationic PSNPs causing an effect on the mitochondrial membrane, it is possible that the mitochondrial calcium could leak out into the cytoplasm. This could result in an increase of cytoplasmic calcium levels and can trigger the apoptotic cascade via cell signaling mechanisms initiating apoptosis. ${ }^{31}$ Previously, Xia et al. already reported such increase in cellular calcium levels in RAW 264.7 cells being exposed to cationic PSNPs of $60 \mathrm{~nm}$ sizes $^{27}$ and our data fit well with their results.

It was shown by different groups before that positive NPs, and not negative NPs, cause holes/pores in suspended lipid bilayers (as an in vitro mimic of lipid bilayer biomembranes like cell or mitochondrial membranes). ${ }^{32,33}$ This is an important finding as creation of such pores in biomembranes could actually contribute to the cytotoxicity of NPs. However, so far creation of holes in the cell membrane of living cells upon exposure to positive NPs has not been observed. In this article, for the first time, with the help of atomic force microscopy (AFM), we were able to directly image the cell membrane topography in NR8383 cells after exposure to differently charged PSNPs. Why cationic PSNPs caused punctures in the cell membrane is not well understood. It has been argued by some groups, based on computational studies, that due to the electrostatic attraction between cationic PSNPs and the (overall) anionic cell membrane, part of the cell membrane protrudes to first cover the PSNPs and then gradually takes up the PSNPs into the lipid bilayers structure of the cell membrane. In contrast, anionic PSNPs get embedded within the membrane lipid bilayer but do not form holes like the cationic ones. ${ }^{34,35}$ Although such explanations on the formation of the holes in the cell membrane by cationic PSNPs need further evidence, it can be said based on the current data that this pore formation phenomenon on cell membranes after exposure to cationic PSNPs may point at a possible mode of action for the adverse effects of cationic PSNPs on cellular integrity. The process of endocytosis might also contribute to the disturbance of membrane integrity. Although by calcein assay, an indirect assessment could be made on the compromised cell membrane integrity after exposure to especially cationic PSNPs, direct evidence for disturbance of membrane structure by PSNPs was obtained by AFM. Previously, some groups already advocated the use of AFM in imaging the surface topography of biological samples including cells. ${ }^{36,37}$ In addition, AFM can be performed in normal and water rich biological conditions making the technique compatible for imaging the surface characteristics of cells. The creation of hole-like structures on the cell membrane by cationic PSNPs can add to the mechanistic understanding of the cytotoxicity of PSNPs. The concentrations applied here for the investigations were non-toxic $\left(1 \mu \mathrm{g} \mathrm{ml}^{-1}\right)$ and hence this discontinuity of the cell membrane may not reflect necrosis. By creating holes in the cell membrane, the cationic PSNPs can cause a disruption in the cell membrane permeability and thus disturb normal cell functioning. The cellular uptake of these fluorescent PNPs has been published before. ${ }^{38}$

Taken together, the results of the present paper point towards membrane disruption as the primary cause for the cytotoxicity of PSNP- $\mathrm{NH}_{2}$. This membrane disruption then leads to disruption of the ETC and ROS production, with oxidative stress as a secondary effect.

\section{Experimental}

\section{PSNPS}

The fluorescent PSNP-NH $\mathrm{N}_{2}$ and PSNP-COOH of 50 and $100 \mathrm{~nm}$ sizes were purchased from Sigma Aldrich Chemie BV. The sizes (while dispersed in water or DMEM/F12-K medium containing $10 \%$ FCS after $4 \mathrm{~h}$ ) and PDI of the PSNPs were checked by DLS and imaged by AFM through contact tapping mode on a mica surface. The surface potentials of the PSNPs were measured by 
$\zeta$-potential measurements (Malvern Zetasizer). The stabilities of these PSNPs suspensions both in water and DMEM/F12-K medium (with FCS) were checked by DLS.

\section{NR8383 cells}

Rat alveolar macrophage (NR8383) cells were obtained from ATCC (Manassas, VA). The NR8383 cells were cultured in 150 $\mathrm{cm}^{2}$ cell culture flasks with $5 \mathrm{ml} 1 \mathrm{~K}$ culture medium (Gibco 21127) supplemented with $10 \%(\mathrm{v} / \mathrm{v})$ heat inactivated fetal calf serum (FCS) in a humidified atmosphere containing $5 \% \mathrm{CO}_{2}$ at $37{ }^{\circ} \mathrm{C}$.

\section{MTT assay}

An NR8383 cell suspension was centrifuged at $140 \mathrm{~g}$ for $5 \mathrm{~min}$ before re-suspending the cell pellet in F12-K medium followed by counting and adjusting the cellular concentration to $2 \times 10^{5}$ cells per $\mathrm{ml}$. The cells were then seeded in a 96-well plate $(50 \mu \mathrm{l}$ per well) and the plate was kept in a $5 \% \mathrm{CO}_{2}$ incubator at $37{ }^{\circ} \mathrm{C}$ for $24 \mathrm{~h}$. Subsequently, $50 \mu \mathrm{l}$ of serial dilutions of different PSNPs in F12-K medium were added to the cells to obtain the required final concentrations $\left(0-100 \mu \mathrm{g} \mathrm{ml} \mathrm{m}^{-1}\right)$. This was followed by incubation for another $4 \mathrm{~h}$ after which $5 \mu \mathrm{l}$ of MTT solution in PBS (5 mg ml $\mathrm{ml}^{-1}$ ) was added to each well and the plate was incubated for another $4 \mathrm{~h}$. Then $100 \mu \mathrm{l}$ of pure dimethysulfoxide (DMSO) was added to each well to dissolve the formazan crystals. The absorption reading of each well was measured at $562 \mathrm{~nm}$ in a 96-well plate reader and the background absorption reading at $612 \mathrm{~nm}$ was subtracted. Mitochondrial metabolic activity for each concentration of PSNPs was expressed as $\%$ of the negative control $\left(0 \mu \mathrm{g} \mathrm{ml} \mathrm{m}^{-1}\right)$ reading.

Medium without PSNPs and medium with Triton-X $(0.1 \%)$ were used as negative and positive controls, respectively. A $4 \mathrm{~h}$ exposure time was selected as the cationic PSNPs already showed significant cytotoxicity within the tested concentration range in $4 \mathrm{~h}$.

MTT assay to investigate protective effects of vitamins $\mathrm{E}$ and $\mathrm{C}$ against the cytotoxicity of DNP, PSNP- $\mathrm{NH}_{2}$ and $\mathrm{H}_{2} \mathrm{O}_{2}$

The NR8383 cells were pre-incubated with $100 \mu \mathrm{M}$ vitamin E or $1 \mathrm{mM}$ vitamin $\mathrm{C}$ and then exposed to DNP (0-75 mM), PSNP$\mathrm{NH}_{2}$ and $\mathrm{H}_{2} \mathrm{O}_{2}(0-1 \mathrm{mM})$. After $4 \mathrm{~h}, 5 \mu \mathrm{l}$ of MTT solution in PBS $\left(5 \mathrm{mg} \mathrm{ml}{ }^{-1}\right)$ was added to each well and the plate was incubated for another $4 \mathrm{~h}$. The purple formazan crystals were then dissolved in $100 \mu \mathrm{l}$ per well DMSO and measured at $562 \mathrm{~nm}$ and $612 \mathrm{~nm}$ (as background). The reading of each well was expressed as \% of the negative control $\left(0 \mu \mathrm{g} \mathrm{ml}{ }^{-1}\right)$.

MTT assay with pre-exposure to buthionine sulphoximine (BSO) or $N$-acetyl cysteine (NAC) to investigate the protective role of cellular GSH

The NR8383 cells were plated with medium containing BSO (100 $\mu \mathrm{M}$ per well) to reduce cellular GSH levels (BuchmillerRouiller et al., 1995) or NAC (10 mM per well) to increase cellular antioxidant levels for $24 \mathrm{~h}$ and $1 \mathrm{~h}$, respectively, before being exposed to 2,4-DNP, PSNP- $\mathrm{NH}_{2}$ and $\mathrm{H}_{2} \mathrm{O}_{2}$ and performing the MTT assay as described above.

\section{Phagocytic index (PI) measurement}

An NR8383 cell suspension $\left(2 \times 10^{5}\right.$ cells per ml $)$ was seeded in a 96-well plate (50 $\mu \mathrm{l}$ per well) in F12-K medium, followed by addition of $50 \mu \mathrm{l}$ per well of serial dilutions of different PSNP in F12-K medium to obtain the required final test concentrations of PSNP $\left(0-100 \mu \mathrm{g} \mathrm{ml}^{-1}\right)$ on the time of incubation. Plain F12-K medium without PSNPs and medium containing $100 \mu \mathrm{M} \mathrm{CuSO}_{4}$ were used as negative and positive controls, respectively. After 4 $\mathrm{h}$, the cells were exposed to yellow green fluorescent latex beads $(1 \mu \mathrm{m}$ size $)$ at a ratio of beads to cells in each well of $50: 1$. After $4 \mathrm{~h}$ of incubation (total exposure time $8 \mathrm{~h}$ ) counting samples were taken from the wells and viewed first under a fluorescent microscope to visualize the fluorescent beads, followed by bright field view to visualize the cells. Samples were also taken out of each well to assess the cell viability by trypan blue exclusion test. The trypan blue exclusion test was performed by adding trypan blue dye to the cell suspension (1:1) before measuring the amount of viable cells under light microscope. The phagocytic index was determined by calculating the average number of fluorescent beads phagocytosed per viable cell and expressed as $\%$ of the negative control $\left(0 \mu \mathrm{g} \mathrm{ml}{ }^{-1}\right)$.

\section{Measurement of intracellular ROS by the DCFH-DA assay}

The NR8383 cell suspension was adjusted to $2 \times 10^{5}$ cells per $\mathrm{ml}$ and seeded in a 96-well plate (50 $\mu \mathrm{l}$ per well) in F12-K medium. $50 \mu \mathrm{l}$ per well of serial dilutions of different PSNPs in F12-K medium were added to obtain the required final test concentrations of PSNPs $\left(0-100 \mu \mathrm{g} \mathrm{ml}^{-1}\right)$. A concentration of $10 \mathrm{mM}$ $\mathrm{H}_{2} \mathrm{O}_{2}$ was used as positive control and $\mathrm{F} 12-\mathrm{K}$ medium without PSNPs as negative control. Immediately after exposure to the PSNPs, $5 \mu \mathrm{l}$ of a $20 \mathrm{mM}$ solution of DCFH-DA (in DMSO) was added to each well and the plates were incubated for $4 \mathrm{~h}$ in a $5 \%$ $\mathrm{CO}_{2}$ atmosphere at $37^{\circ} \mathrm{C}$. The fluorescence was then measured on a spectrofluorometer at $\lambda_{\mathrm{ex}}=485 \mathrm{~nm}$ and $\lambda_{\mathrm{em}}=538 \mathrm{~nm}$. The fluorescence induction factor for each concentration of PSNPS was calculated by dividing the reading of each well by the average reading of the negative control $\left(0 \mu \mathrm{g} \mathrm{ml}{ }^{-1}\right)$ and expressed as \% of the control. Control experiments were performed by incubating the PSNPs at their test concentrations with DCFH-DA in the absence of cells to check the possibility of a positive fluorescence reading caused by reaction of DCFH-DA with PSNPs alone.

\section{Measurement of intracellular ROS production by DCFH-DA assay in presence of DNP and $\mathrm{H}_{2} \mathrm{O}_{2}$}

$50 \mu \mathrm{l}$ of an NR8383 cell suspension ( $2 \times 10^{5}$ cells per $\left.\mathrm{ml}\right)$ in F12$\mathrm{K}$ medium, containing $100 \mu \mathrm{M}$ vitamin $\mathrm{E}$ or $1 \mathrm{mM}$ vitamin $\mathrm{C}$, or no added antioxidants (negative control), was seeded in each well of a 96-well plate and incubated for $24 \mathrm{~h}$. The vitamin C was added after $22 \mathrm{~h}$ of incubation, making the pre-incubation time for vitamin $\mathrm{E}$ and vitamin $\mathrm{C}, 24 \mathrm{~h}$ and $2 \mathrm{~h}$, respectively. Different DNP, cationic PSNP- $\mathrm{NH}_{2}$ and $\mathrm{H}_{2} \mathrm{O}_{2}$ dilutions were then added to obtain the test dilutions (0-75 mM for DNP, $0-100 \mu \mathrm{g} \mathrm{ml}^{-1}$ for 
PSNP- $\mathrm{NH}_{2}$ and 0-1 mM for $\mathrm{H}_{2} \mathrm{O}_{2}$ ). $5 \mu$ l of a $20 \mathrm{mM}$ DCFH-DA solution in DMSO was added to each well after $4 \mathrm{~h}$ and incubated for further $4 \mathrm{~h}$ (total exposure time of $8 \mathrm{~h}$ ). The fluorescence was measured $\left(\lambda_{\mathrm{ex}}=485 \mathrm{~nm}, \lambda_{\mathrm{em}}=538 \mathrm{~nm}\right)$ and the induction factors for each concentration of PSNP were obtained by expressing the readings of the wells as \% of the negative control. Control experiments were performed by incubating the DNP, PSNP- $\mathrm{NH}_{2}$ and $\mathrm{H}_{2} \mathrm{O}_{2}$ at their test concentrations with DCFH-DA to exclude any interference with the fluorescence.

\section{Measurement of mitochondrial permeability transition pore opening}

The NR8383 cell suspension was adjusted to $2 \times 10^{5}$ cells per $\mathrm{ml}$ and seeded in a $96-$ well plate $(50 \mu \mathrm{l}$ per well $)$ in F12-K medium. Per well $50 \mu \mathrm{l}$ of serial dilutions of different PSNPs in F12-K medium were added to obtain the required final test concentrations of PSNPs $\left(0-100 \mu \mathrm{g} \mathrm{ml}^{-1}\right)$. The mitochondrial membrane potential $\left(\Delta \Psi_{\mathrm{m}}\right)$ was measured after $4 \mathrm{~h}$ of exposure by a commercially available kit from Invitrogen (MitoProbe ${ }^{\mathrm{TM}}$ Transition Pore Assay Kit; catalogue no. M34153) and expressed as $\%$ of the negative control $\left(0 \mu \mathrm{g} \mathrm{m}{ }^{-1}\right)$. The assay detects mitochondrial permeability transition pore opening as an indirect measurement for effects on mitochondrial membrane potential $\left(\Delta \Psi_{\mathrm{m}}\right)$. In this kit, a non-fluorescent acetomethoxy derivative of calcein (calcein-AM) is administered which upon passively entering the cells and accumulating in the cytoplasm as well as in the mitochondria, gets cleaved by intracellular esterases to release ionic and fluorescent calcein. Due to its strong ionic nature, this released calcein cannot cross the mitochondrial/ plasma membrane and thus can be detected by fluorescence inside the cell. In this kit, the fluorescence coming from the calcein in the cytoplasm is quenched with the addition of cobalt chloride $\left(\mathrm{CoCl}_{2}\right)$, so that only the fluorescence coming from the mitochondria will be detected. A $100 \mu \mathrm{M}$ solution of ionomycin in DMSO (supplied with the kit) and F12-K medium without PSNPs were used as positive and negative controls, respectively.

\section{Measurement of cellular ATP content}

The NR8383 cell suspension was adjusted to $2 \times 10^{5}$ cells per $\mathrm{ml}$ and seeded in a 96-well plate ( $50 \mu \mathrm{l}$ per well) in F12-K medium. A $50 \mu \mathrm{l}$ per well of serial dilutions of different PSNPs in F12-K medium were added to obtain the required final test concentrations of PSNPs $\left(0-100 \mu \mathrm{g} \mathrm{ml}^{-1}\right)$. The cellular ATP was then measured after $4 \mathrm{~h}$ of exposure by a commercially available kit from Invitrogen (catalogue no. FLASC) and expressed as \% of negative control $\left(0 \mu \mathrm{g} \mathrm{ml}^{-1}\right)$. In this kit, the ATP concentration is measured by the interaction between cellular ATP and luciferin in the presence of $\mathrm{Mg}^{2+}$, producing adenyl luciferin which upon oxidation produces light. A $75 \mathrm{mM}$ solution of DNP (in DMSO) and F12-K medium without PSNPs were used as positive (i.e. with known effects of ATP depletion) and negative controls, respectively.

\section{Measurement of cytoplasmic calcium}

The NR8383 cell suspension was adjusted to $2 \times 10^{5}$ cells per $\mathrm{ml}$ and seeded in a 96-well plate $(50 \mu \mathrm{l}$ per well) in F12-K medium.
Per well $50 \mu \mathrm{l}$ of serial dilutions of different PSNPs in F12-K medium were added to obtain the required final test concentrations of PSNPs $\left(0-100 \mu \mathrm{g} \mathrm{ml}^{-1}\right)$. The cytoplasmic free calcium was then measured after $4 \mathrm{~h}$ of exposure by a commercially available kit from Invitrogen (Fluo-4 Direct ${ }^{\mathrm{TM}}$ Calcium Assay Kit; catalogue no. F10472) and expressed as \% of negative control $\left(0 \mu \mathrm{g} \mathrm{ml}^{-1}\right)$. F12-K medium without PSNPs was used as negative control.

\section{CLSM}

The NR8383 cell suspension was adjusted to $2 \times 10^{5}$ cells per $\mathrm{ml}$ and seeded in a 96-well plate (50 $\mu \mathrm{l}$ per well) in F12-K medium. Per well $50 \mu \mathrm{l}$ of serial dilutions of different PSNPs in F12-K medium were added to obtain a required non-toxic concentration of PSNPs $\left(1 \mu \mathrm{g} \mathrm{ml} \mathrm{m}^{-1}\right)$. After $4 \mathrm{~h}$ of exposure, samples were taken out and put on a glass slide before examining them under oil immersion microscope $(100 \times)$ and then visualizing the cells under a Zeiss Axiovert 200M-Exciter confocal laser scanning microscope $\left(\lambda_{\mathrm{ex}}=543 \mathrm{~nm} ; \lambda_{\mathrm{em}}=620 \mathrm{~nm}\right)$. Different samples were measured with the same set up of similar resolution, aperture width and image gain. The relative cellular uptake of $100 \mathrm{~nm}$ cationic and anionic PSNPs were expressed as an arithmetic mean of data obtained from 20 individual cells from at least five different experiments $(n=5)$. Cells exposed to only F12-K medium were used as control.

\section{Calcein-AM assay}

The NR8383 cell suspension $\left(2 \times 10^{5}\right.$ cells per $\left.\mathrm{ml}\right)$ was exposed to $1 \mu \mathrm{M}$ calcein-AM for $1 \mathrm{~h}$. The cells were then washed with PBS by repeated centrifugation and then exposed to non-toxic concentration of PSNPs $\left(1 \mu \mathrm{g} \mathrm{ml} \mathrm{m}^{-1}\right)$. After $4 \mathrm{~h}$ of exposure, samples were taken out and put on a glass slide before examining it under oil immersion microscope $(100 \times)$ and then visualizing the cells under a Zeiss confocal laser scanning microscope $\left(\lambda_{\mathrm{ex}}=488 \mathrm{~nm} ; \lambda_{\mathrm{em}}=538 \mathrm{~nm}\right)$. Different samples were measured $(n=5)$ with the same set up of similar resolution, aperture width and image gain. Cells exposed to only calcein were used as control.

\section{AFM}

After exposure to PSNPs $\left(1 \mu \mathrm{g} \mathrm{ml} \mathrm{m}^{-1}\right)$ for $4 \mathrm{~h}$, cellular samples (from different cultures) were taken from a NR8383 cell suspension $\left(2 \times 10^{5}\right.$ cells per $\left.\mathrm{ml}\right)$ before placing them on mica slides. The samples were then checked by AFM in contact tapping mode with a silicon nitride tip of an average diameter of $30 \mathrm{~nm}$. Each time an area of $2 \times 2 \mu \mathrm{m}$ was scanned and then the height tracings as well as the three dimensional depictions of the surfaces were made. The roughness $(r)$ was calculated for the area scanned by the computer software. In total, five cells ( $n$ $=5$ ) were measured for each type of PSNPs.

\section{Statistical analysis}

Each experiment was repeated three times $(n=3)$ unless mentioned otherwise and the results are shown as mean \pm standard error of mean after analysis and plotting by Origin Pro 
(version 8.0) software. Data points were taken as statistically significantly different if $p<0.05$ compared to the negative control (unless stated otherwise) and marked with an asterisk (*) symbol. The $\mathrm{EC}_{50}$ values were determined by the Origin Pro software after setting up a trendline to the curves.

\section{Acknowledgements}

The authors would like to thank graduate school VLAG, QNano and Wageningen UR strategic research programme Bionanotechnology (IPOP/BioNano) for funding. Dr Marcel Giesbers is thanked for help with the AFM measurements.

\section{References}

1 M. J. D. Clift, S. Bhattacharjee, D. M. Brown and V. Stone, Toxicol. Lett., 2010, 198, 358-365.

2 K. Donaldson and V. Stone, in Nanotechnology: Consequences for Human Health and the Environment, The Royal Society of Chemistry, 2007, vol. 24.

3 S. Bhattacharjee, L. H. J. de Haan, N. M. Evers, X. Jiang, A. T. M. Marcelis, H. Zuilhof, I. M. C. M. Rietjens and G. M. Alink, Part. Fibre Toxicol., 2010, 7, 25.

4 K. Greish, G. Thiagarajan, H. Herd, R. Price, H. Bauer, D. Hubbard, A. Burckle, S. Sadekar, T. Yu, A. Anwar, A. Ray and H. Ghandehari, Nanotoxicology, 2012, 6, 713-723.

5 K. Kawata, M. Osawa and S. Okabe, Environ. Sci. Technol., 2009, 43, 6046-6051.

6 S. M. Hussain, K. L. Hess, J. M. Gearhart, K. T. Geiss and J. J. Schlager, Toxicol. In Vitro, 2005, 19, 975-983.

7 C. Monteiller, L. Tran, W. MacNee, S. Faux, A. Jones, B. Miller and K. Donaldson, Occup. Environ. Med., 2007, 64, 609-615.

8 K. Yu, C. Grabinski, A. Schrand, R. Murdock, W. Wang, B. Gu, J. Schlager and S. Hussain, J. Nanopart. Res., 2009, 11, 15-24.

9 M. Y. Wani, M. A. Hashim, F. Nabi and M. A. Malik, Adv. Phys. Chem., 2011, 450912-450927.

10 H. Zhang, T. Xia, H. Meng, M. Xue, S. George, Z. Ji, X. Wang, R. Liu, M. Wang, B. France, R. Rallo, R. Damoiseaux, Y. Cohen, K. A. Bradley, J. I. Zink and A. E. Nel, ACS Nano, 2011, 5, 2756-2769.

11 A. E. Vercesi, R. Docampo and S. N. J. Moreno, Mol. Biochem. Parasitol., 1992, 56, 251-257.

12 A. Verma, O. Uzun, Y. Hu, Y. Hu, H.-S. Han, N. Watson, S. Chen, D. J. Irvine and F. Stellacci, Nat. Mater., 2008, 7, 588-595.

13 T. Cedervall, I. Lynch, S. Lindman, T. Berggård, E. Thulin, H. Nilsson, K. A. Dawson and S. Linse, Proc. Natl. Acad. Sci. U. S. A., 2007, 104, 2050-2055.

14 I. Lynch, T. Cedervall, M. Lundqvist, C. Cabaleiro-Lago, S. Linse and K. A. Dawson, Adv. Colloid Interface Sci., 2007, 134-135, 167-174.

15 A. Alkilany and C. Murphy, J. Nanopart. Res., 2010, 12, 23132333.

16 E. Frohlich, Int. J. Nanomed., 2012, 7, 5577-5591.
17 C. Hoskins, A. Cuschieri and L. Wang, J. Nanobiotechnol., 2012, 10, 15.

18 M. Schulz, A. Olubummo and W. H. Binder, Soft Matter, 2012, 8, 4849-4864.

19 M. Auffan, J. Rose, J. Y. Bottero, G. V. Lowry, J. P. Jolivet and M. R. Wiesner, Nat. Nanotechnol., 2009, 4, 634-641.

20 Y. Liu, W. Li, F. Lao, Y. Liu, L. Wang, R. Bai, Y. Zhao and C. Chen, Biomaterials, 2011, 32, 8291-8303.

21 H. Fritz, M. Maier and E. Bayer, J. Colloid Interface Sci., 1997, 195, 272-288.

22 H. Chen, Q. C. Zou, H. Yu, M. Peng, G. W. Song, J. Z. Zhang, S. G. Chai, Y. Zhang and C. E. Yan, Microchim. Acta, 2010, 168, 331-340.

23 S. Bhattacharjee, I. M. C. M. Rietjens, M. P. Singh, T. M. Atkins, T. K. Purkait, Z. Xu, S. Regli, A. Shukaliak, R. J. Clark, B. S. Mitchell, G. M. Alink, A. T. M. Marcelis, M. J. Fink, J. G. C. Veinot, S. M. Kauzlarich and H. Zuilhof, Nanoscale, 2013, 5, 4870-4883.

24 W. H. de Jong and P. J. A. Borm, Int. J. Nanomed., 2008, 3, 133-149.

25 P. H. Hoet, I. Bruske-Hohlfeld and O. V. Salata, J. Nanobiotechnol., 2004, 2, 12.

26 T. Xia, M. Kovochich, M. Liong, J. I. Zink and A. E. Nel, ACS Nano, 2008, 2, 85-96.

27 T. Xia, M. Kovochich, J. Brant, M. Hotze, J. Sempf, T. Oberley, C. Sioutas, J. I. Yeh, M. R. Wiesner and A. E. Nel, Nano Lett., 2006, 6, 1794-1807.

28 T. Mocan, S. Clichici, L. Agosston-Coldea, L. Mocan, Ş. Şimon, I. Ilie, A. Biriş and A. Mureşan, Acta Physiol. Hung., 2010, 97, 247-255.

29 V. Salnikov, Y. O. Lukyánenko, C. A. Frederick, W. J. Lederer and V. Lukyánenko, Biophys. J., 2007, 92, 1058-1071.

30 Ö. F. Karataş, E. Sezgin, Ö. Aydın and M. Çulha, Colloids Surf., B, 2009, 71, 315-318.

31 M. R. Duchen, J. Physiol., 2000, 529, 57-68.

32 J. Chen, J. A. Hessler, K. Putchakayala, B. K. Panama, D. P. Khan, S. Hong, D. G. Mullen, S. C. DiMaggio, A. Som, G. N. Tew, A. N. Lopatin, J. R. Baker, M. M. B. Holl and B. G. Orr, J. Phys. Chem. B, 2009, 113, 11179-11185.

33 P. R. Leroueil, S. A. Berry, K. Duthie, G. Han, V. M. Rotello, D. Q. McNerny, J. R. Baker, B. G. Orr and M. M. Banaszak Holl, Nano Lett., 2008, 8, 420-424.

34 Y. Li, X. Chen and N. Gu, J. Phys. Chem. B, 2008, 112, 1664716653.

35 H. Lee and R. G. Larson, J. Phys. Chem. B, 2008, 112, 1227912285.

36 A. Raman, S. Trigueros, A. Cartagena, A. P. Z. Stevenson, M. Susilo, E. Nauman and S. A. Contera, Nat. Nanotechnol., 2011, 6, 809-814.

37 S. Nawaz, P. Sánchez, K. Bodensiek, S. Li, M. Simons and I. A. T. Schaap, PLoS One, 2012, 7, e45297.

38 S. Bhattacharjee, D. Ershov, J. van der Gucht, I. M. C. M. Rietjens, H. Zuilhof and A. T. M. Marcelis, Nanotoxicology, 2013, 7, 71-84. 